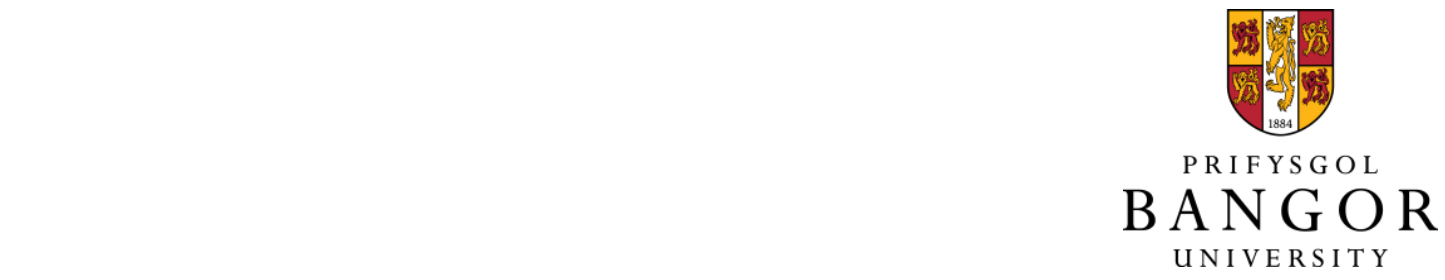

Comparing spatial and temporal transferability of hydrological model parameters

Patil, S.D.; Stieglitz, M.

Journal of Hydrology

DOI:

10.1016/j.jhydrol.2015.04.003

Published: 09/04/2015

Peer reviewed version

Cyswllt i'r cyhoeddiad / Link to publication

Dyfyniad o'r fersiwn a gyhoeddwyd / Citation for published version (APA):

Patil, S. D., \& Stieglitz, M. (2015). Comparing spatial and temporal transferability of hydrological model parameters. Journal of Hydrology, 525, 409-417.

https://doi.org/10.1016/j.jhydrol.2015.04.003

\footnotetext{
Hawliau Cyffredinol / General rights

Copyright and moral rights for the publications made accessible in the public portal are retained by the authors and/or other copyright owners and it is a condition of accessing publications that users recognise and abide by the legal requirements associated with these rights.

- Users may download and print one copy of any publication from the public portal for the purpose of private study or research.

- You may not further distribute the material or use it for any profit-making activity or commercial gain

- You may freely distribute the URL identifying the publication in the public portal ?
}

Take down policy

If you believe that this document breaches copyright please contact us providing details, and we will remove access to the work immediately and investigate your claim. 
NOTICE: This is the author's version of a work that was peer reviewed and accepted for publication in the Journal of Hydrology. Changes resulting from the publishing process, such as editing, corrections, structural formatting, and other quality control mechanis ms may not be reflected in this document. A definitive version was published in JOURNAL OF HYDROLOGY, VOL 525, DOI http://dx.doi.org/10.1016/j.jhydrol.2015.04.003.

\section{Comparing spatial and temporal transferability of hydrological}

\section{model parameters}

Sopan D. Patil ${ }^{1}$, Marc Stieglitz ${ }^{2}$

${ }^{1}$ School of Environment, Natural Resources and Geography,

Bangor University,

Deiniol Road, Bangor, LL57 2UW, United Kingdom

${ }^{2}$ School of Civil and Environmental Engineering,

Georgia Institute of Technology,

790 Atlantic Drive, Atlanta, GA 30332, United States of America

Submission to: Journal of Hydrology

Correspondence to: Sopan D. Patil (email: s.d.patil@ bangor.ac.uk, Tel: +44 1248 388294)

\section{Highlights:}

1) We compare three different schemes for transfer of hydrological model parameters

2) Temporal transfer scheme outperforms spatial and spatiotemporal transfer schemes

3) Differences between spatial and spatiotemporal transfer schemes are negligible

4) Temporal gap in calibration and validation periods reduces difference among schemes 


\section{Abstract}

2 Operational use of hydrological models requires the transfer of calibrated parameters either in

3 time (for streamflow forecasting) or space (for prediction at ungauged catchments) or both.

4 Although the effects of spatial and temporal parameter transfer on catchment streamflow

5 predictions have been well studied individually, a direct comparison of these approaches is

6 much less documented. Here, we compare three different schemes of parameter transfer, viz.,

7 temporal, spatial, and spatiotemporal, using a spatially lumped hydrological model called

8 EXP-HYDRO at 294 catchments across the continental United States. Results show that the

9 temporal parameter transfer scheme performs best, with lowest decline in prediction

10 performance (median decline of $4.2 \%$ ) as measured using the Kling-Gupta efficiency metric.

11 More interestingly, negligible difference in prediction performance is observed between the spatial and spatiotemporal parameter transfer schemes (median decline of $12.4 \%$ and $13.9 \%$ respectively). We further demonstrate that the superiority of temporal parameter transfer scheme is preserved even when: (1) spatial distance between donor and receiver catchments is reduced, or (2) temporal lag between calibration and validation periods is increased. Nonetheless, increase in the temporal lag between calibration and validation periods reduces the overall performance gap between the three parameter transfer schemes. Results suggest that spatiotemporal transfer of hydrological model parameters has the potential to be a viable option for climate change related hydrological studies, as envisioned in the "trading space for time" framework. However, further research is still needed to explore the relationship between spatial and temporal aspects of catchment hydrological variability.

23 Keywords: Hydrological model; parameter transfer; catchment; streamflow prediction 
All hydrological models contain parameters whose values must be calibrated by comparing the observed and simulated streamflow values from the past record [Refsgaard, 1997; Beven, 2001]. Calibrated parameters represent the unique combination of climatic and physiographic factors that influence the hydrological behaviour of a catchment [Merz and Blöschl, 2004; Wagener and Wheater, 2006]. However, operational use of hydrological models is always outside of the calibration period and/or catchment, which is where the parameters face their true test [Kleměs, 1986; Refsgaard and Knudsen, 1996; Coron et al., 2012]. Parameter transfer away from this calibration domain can be in time (for streamflow forecasting) or space (for prediction at ungauged catchments) or both. straightforward procedure used in catchment hydrological modelling. The first step involves choosing a specific historical time period for which all the input and output data required for running the model are available for the catchment. These data are used to calibrate the model parameters by finding the best match between the simulated and observed streamflow values. This procedure is followed by the application of the calibrated model at some other time period in the same catchment. Klemeš [1986] recommends that testing of hydrological models outside the calibration period is critical to establish their credibility as useful forecasting tools. An implicit assumption here is that the calibrated model parameters are temporally stable, i.e., they are suitable for application beyond the calibration period. However, numerous recent studies have shown that hydrological model parameters are not always temporally stable [Merz et al., 2011; Brigode et al., 2013; Westra et al., 2014], and their values depend on the duration as well as the specific physioclimatic conditions of the calibration period [Xia et al., 2004; Juston et al., 2009; Vaze et al., 2010; Razavi and Tolson, 
parameters of a spatially lumped hydrological model and found that parameter values varied significantly when calibrated to different parts of the hydrograph. Merz et al. [2011] calibrated the parameters of a semi-distributed version of HBV model for six consecutive 5 year periods between 1976 and 2006 at 273 Austrian catchments, and found that (1) optimal parameter values were variable across the six calibration periods, and (2) the assumption of time invariant parameters had a significant impact on model simulations outside the calibration period. Similar findings were reported by Coron et al. [2012] in their study on temporal parameter transfer using three rainfall-runoff models at 216 catchments in southeast Australia. Razavi and Tolson [2013] compared three different calibration approaches for the SWAT2000 model at a catchment in the state of New York, USA and concluded that “...model calibration solely to a short data period may lead to a range of performances from poor to very well depending on the representativeness of the short data period which is typically not known a priori”.

Spatial transfer of calibrated parameters is another widely used procedure in catchment hydrological modelling and is primarily required for streamflow prediction at ungauged basins (PUB) [Sivapalan et al., 2003]. A considerable amount of research has been conducted over the years in the development and comparison of approaches to transfer hydrological model parameters from gauged to ungauged catchments [Post and Jakeman, 1999; Kokkonen et al., 2003; McIntyre et al., 2005; Young, 2006; Oudin et al., 2008; Zhang and Chiew, 2009; Patil and Stieglitz, 2014]. Blöschl et al. [2013] and Hrachowitz et al. [2013] provide a comprehensive summary and synthesis of the progress made in PUB research during the International Association of Hydrological Sciences' (IAHS) PUB decade initiative (2003-2012) [Sivapalan et al., 2003]. Donor gauged catchments, from which model parameters can be transferred to the receiver ungauged catchments, are typically identified using an approach that is either based on spatial proximity or physical similarity to the 
ungauged catchments. Oudin et al. [2008] compared the spatial proximity and physical similarity approaches at 913 catchments in France and found that the spatial proximity approach outperformed the physical similarity approach. Zhang and Chiew [2009] tested multiple parameter transfer approaches at 210 catchments in southeast Australia and found that an integrated similarity approach that combined spatial proximity and physical similarity slightly outperformed the spatial proximity approach. Patil and Stieglitz [2014] compared two different methods of spatial parameter transfer at 323 catchments in the United States and found that simulation performance at ungauged catchments is more sensitive to the types of parameters that are transferred than to the method used for transferring them. However, regardless of the chosen approach, spatial parameter transfer tends to cause deterioration in simulation performance (compared to calibration) due to the differences in physiographic properties and meteorological inputs between the donor and receiver catchments.

Although hydrological model simulation following temporal and/or spatial parameter transfer is expected to cause deterioration in catchment streamflow prediction, not many studies have focused on a direct comparison of these two approaches. A few PUB focused studies that have made such a comparison show results that range from a large performance difference between temporal and spatial parameter transfer (in favour of temporal) [Merz and Blöschl, 2004; Parajka et al., 2005] to minor performance difference between them [Oudin et al., 2008]. In our view, further exploration is therefore needed on how the spatial and temporal parameter transfer approaches compare against each other, especially in the context of increasing appeal and popularity of the "trading space for time" approaches that are proposed for assessing the hydrological implications of anthropogenic climate change [Wagener et al., 2010; Peel and Blöschl, 2011; Singh et al., 2011; Ehret et al., 2014; Refsgaard et al., 2014]. The trading space for time framework assumes that the spatial variability in catchment hydrological properties (including model parameters) can be used as 
a proxy for the climate change induced temporal variability in those properties [Merz et al., 2011]. Studies such as Singh et al. [2011, 2014] have already demonstrated that the spatial parameter regionalization techniques developed for PUB can also be applied to make temporal modifications in model parameters for streamflow predictions under change (PUC) [Montanari et al., 2013]. Therefore, we argue that a systematic comparison of the spatial and temporal parameter transfer approaches is likely to provide further insights into the connections between the PUB and PUC paradigms, and could even help refine the trading space for time methods.

In this paper, we compare three schemes of model parameter transfer, viz., temporal, spatial, and spatiotemporal, using a hydrological model called EXP-HYDRO [Patil and Stieglitz, 2014; Patil et al., 2014a, 2014b] at 294 catchments across the continental United States. The temporal parameter transfer scheme is implemented using a split-sample test procedure where the available data is divided into two periods, one for calibration and the other for validation. For the spatial parameter transfer scheme, we use the nearest neighbour catchment as a donor of calibrated parameters. Comparison of different spatial parameter transfer techniques is beyond the scope of this study (and has already been done by Patil and Stieglitz [2014]). In the spatiotemporal parameter transfer scheme, calibrated model parameters are transferred simultaneously in the spatial (to the nearest neighbour catchment) and temporal (to a different time period) domain.

\section{Data and Methods}

\subsection{Hydrological Model}

We use the spatially lumped version of EXP-HYDRO model [Patil and Stieglitz, 2014; Patil et al., 2014a, 2014b] to simulate daily streamflow (Figure 1). This model solves the following two coupled ordinary differential equations simultaneously at each time step: 


$$
\frac{d S_{\text {Snow }}}{d t}=P_{\text {Snow }}-Q_{\text {Melt }}
$$

$$
\frac{d S}{d t}=P_{\text {Rain }}+Q_{\text {Melt }}-E T-Q_{\text {Bucket }}-Q_{\text {Spill }}
$$

126 where $S$ and $S_{\text {Snow }}$ are, respectively, the amounts of stored water (mm) in the catchment and 127 snow accumulation buckets. $P_{\text {Snow }}$ and $P_{\text {Rain }}$ are the snowfall and rainfall amounts (mm/day).

$128 E T$ is the actual evapotranspiration (mm/day) from the catchment bucket. $Q_{\text {Melt }}$ is the 129 snowmelt (mm/day) from the snow accumulation bucket, $Q_{\text {Bucket }}$ is the subsurface runoff 130 (mm/day) generated from the catchment bucket, and $Q_{\text {Spill }}$ is the capacity-excess surface 131 runoff (mm/day) that is generated when the catchment bucket is filled to capacity. The incoming daily precipitation $P$ is classified as snowfall or rainfall based on the 133 following conditions:

134 If $T_{a}<T_{\min }$,

$$
\begin{aligned}
& P_{\text {Snow }}=P \\
& P_{\text {Rain }}=0
\end{aligned}
$$

136 Else,

$$
\begin{aligned}
& P_{\text {Snow }}=0 \\
& P_{\text {Rain }}=P
\end{aligned}
$$

138 where $T_{a}$ is the actual air temperature on a given day, $T_{\min }$ is the air temperature below which 139 the precipitation occurs as snowfall and falls directly into the snow accumulation bucket.

140 Snowmelt $Q_{\text {Melt }}$ is modelled using a simple thermal degree day model as follows:

141 If $T_{a}>T_{\max }$,

$$
Q_{\text {Melt }}=\min \left\{S_{\text {Snow }} D_{f} \cdot\left(T_{a}-T_{\max }\right)\right\}
$$

143 Else, 


$$
Q_{\text {Melt }}=0
$$

where $T_{\max }$ is the air temperature above which the snow in snow accumulation bucket starts melting, and $D_{f}$ is the thermal degree day factor that controls the rate of snowmelt.

147 Evapotranspiration $E T$ from the catchment bucket is calculated as follows:

$$
E T=P E T \cdot\left(\frac{S}{S_{\text {max }}}\right)
$$

where $P E T$ is the potential evapotranspiration ( $\mathrm{mm} / \mathrm{day}$ ), and is calculated from the daily air temperature using Hamon's formula [Hamon, 1963]. $S_{\max }$ is the total storage capacity (mm) of the catchment bucket. The surface and subsurface runoff generated from the catchment bucket are calculated as follows: If $S \leq S_{\max }$, If $S>S_{\max }$,

$$
\begin{gathered}
Q_{\text {Bucket }}=Q_{\text {max }} \cdot \exp \left(-f \cdot\left(S_{\max }-S\right)\right) \\
Q_{\text {Spill }}=0
\end{gathered}
$$

157 where $Q_{\max }$ is the maximum subsurface runoff produced (mm/day) when the catchment bucket reaches its capacity, and $f$ is the parameter controlling the storage-dependent exponential decline in subsurface runoff $(1 / \mathrm{mm})$. Daily streamflow at the catchment outlet is 160 the sum of $Q_{\text {Bucket }}$ and $Q_{\text {Spill }}$.

We have now made the entire source code of the spatially lumped version of the EXPHYDRO model (described above) freely available to the research community. This source code is written in Python ${ }^{\circledR}$ programming language and can be downloaded from the following web link: http://sopanpatil.weebly.com/exp-hydro.html. 


\subsection{Model Calibration}

There are six calibration parameters in the EXP-HYDRO model: $f, S_{\max }, Q_{\max }, D_{f}$, $T_{\max }$, and $T_{\min }$. For each catchment, we calibrate these six model parameters using the Particle Swarm Optimisation (PSO) algorithm [Kennedy and Eberhart, 1995]. PSO is a stochastic population-based search algorithm that has been used in numerous hydrological studies for model parameter calibration [Gill et al., 2006; Goswami and O'Connor, 2007; Liu, 2009; Zhang et al., 2009]. PSO is initialised with a group of random particles (parameter sets in our case), and this 'swarm' of particles searches for an optimal solution within the parameter domain by iteratively updating the velocity and position of each particle. We initialise the PSO algorithm with 10 randomly generated EXP-HYDRO parameter sets (sampled from a uniform distribution) and allow for a maximum of 50 swarm iterations to find the optimal solution. The upper and lower bound values of all six parameters are same as those in Patil and Stieglitz [2014]. We use Kling-Gupta efficiency (KGE) [Gupta et al., 2009] as the objective function that is to be maximised during calibration:

$$
K G E=1-\sqrt{(r-1)^{2}+(\alpha-1)^{2}+(\beta-1)^{2}}
$$

where $r$ is the Pearson's linear correlation coefficient between the observed and simulated streamflow, $\alpha$ is the ratio of standard deviations of observed and simulated streamflow, and $\beta$ is the ratio of mean values of observed and simulated streamflow. The value of KGE varies from $-\infty$ to 1 , with $\mathrm{KGE}=1$ being a perfect fit between the observed and simulated values.

As shown by Gupta et al. [2009], KGE consists of three main components, correlation $\left(g_{1}\right)$, variability $\left(g_{2}\right)$, and bias $\left(g_{3}\right)$, whose relative contribution to the KGE value varies from 0 to 1 and is calculated as follows: 


$$
g_{i}=\frac{G_{i}}{\sum_{j=1}^{3} G_{j}}
$$

and,

190

$$
\begin{aligned}
G_{1} & =(r-1)^{2} \\
G_{2} & =(\alpha-1)^{2} \\
G_{3} & =(\beta-1)^{2}
\end{aligned}
$$

191

192

\subsection{Study Catchments}

We begin the catchment selection process by implementing the EXP-HYDRO model at 756 catchments in the continental United States (Figure 2a). These are the same catchments that have been used in our two previous studies [Patil and Stieglitz, 2012, 2014]; they belong to the U. S. Geological Survey's Hydro-Climate Data Network (HCDN) [Slack et $a l ., 1993$ ] and have a continuous daily streamflow record from water year (WY) 1970 to 1988 (i.e., 1st October, 1969 to 30th September, 1988). Daily precipitation and air temperature data for each catchment are obtained from the gridded meteorological dataset developed by Maurer et al. [2002]. This data has a spatial resolution of 0.125 degree and covers the entire continental United States.

We split the timeline from WY 1970 to 1988 into the following three periods: WY 1970 is the spin-up period that is not used for parameter calibration, WY 1971 to 1978 is calibration period 1, and WY 1979 to 1988 is calibration period 2 (see Figure 2b). For each catchment, we calibrate the EXP-HYDRO model parameters separately for calibration periods 1 and 2 using the methods described in Section 2.2. Only those catchments where the simulated streamflow provides KGE $>0.6$ for both calibration periods are retained as our study catchments. This is done to ensure that only those catchments for which the EXPHYDRO model structure seems suitable for providing good hydrological simulations are used for any further analyses. The above condition reduces the number of acceptable study 
catchments to 294 (Figure 2a). The geographic distribution of the acceptable catchments is similar to that obtained by Patil and Stieglitz [2014]. The drainage area of the study catchments ranges from $24 \mathrm{~km}^{2}$ to $4790 \mathrm{~km}^{2}$, with median drainage area of $620 \mathrm{~km}^{2}$. The majority of catchments are located in the eastern part of the continental United States, to the east of Mississippi River. In the western United States, the study catchments are primarily located along the Rocky, Cascade and Pacific Coastal mountain ranges. Mean annual precipitation among the study catchments ranges from $340 \mathrm{~mm}$ to $2556 \mathrm{~mm}$ (median $=1160$ $\mathrm{mm})$.

\subsection{Parameter Transfer Schemes}

For the 294 study catchments, we test the following three schemes of model parameter transfer:

(1) Temporal transfer: For the same catchment, model parameters from calibration period 1

(3) Spatiotemporal transfer: Model parameters of a catchment are obtained from its nearest neighbour catchment across different time periods (i.e., from calibration period 1 to 2 , and vice versa).

\section{Results}

We first compare the simulation performance of EXP-HYDRO model that is obtained across the two calibration periods. Figure 3 shows a 1:1 comparison of the KGE values obtained at the 294 catchments during calibration periods 1 and 2. The relationship between calibrated KGE values of the two periods is somewhat weak (Pearson's $r=0.53$ ), with data 
points scattered along both sides of the 1:1 line. Figure 4 shows the comparison of $g_{1}, g_{2}$, and $g_{3}$ (the three components of KGE) during calibration periods 1 and 2. Similar to KGE, a weak relationship exists between the values obtained at these two different periods $(r=0.55$ for $g_{1}, r=0.4$ for $g_{2}, r=0.65$ for $g_{3}$ ). Figures 5a-f show a 1:1 comparison of the values of all six EXP-HYDRO parameters during calibration periods 1 and 2. The relationship among parameter values across the two calibration periods is strongest for $f(r=0.81$, Figure 5a), followed by $S_{\max }\left(r=0.59\right.$, Figure 5b), $D_{f}(r=0.36$, Figure $5 \mathrm{~d}), Q_{\max }(r=0.26$, Figure 5c), $T_{\min }\left(r=0.26\right.$, Figure 5e), and $T_{\max }(r=0.17$, Figure 5f).

We next compare the performance of EXP-HYDRO model across the three parameter transfer schemes. Figure 6 shows a box-plot comparison of the KGE values among the following four modelling scenarios: calibration, temporal transfer, spatial transfer, and spatiotemporal transfer. Note that the KGE values shown in Figure 6 are the average values of two sub-scenarios that are present in each scenario. For example, KGE of each catchment in the calibration scenario is an average of its KGE values from calibration period 1 and calibration period 2. As seen in Figure 6, the overall model performance is highest for the calibration scenario (median KGE $=0.72$ ), followed by temporal transfer (median KGE = 0.69 ; decline of $4.2 \%$ (compared to calibration)), spatial transfer (median $\mathrm{KGE}=0.63$; decline of $12.4 \%$ ), and spatiotemporal transfer (median $\mathrm{KGE}=0.62$; decline of $13.9 \%$ ) scenarios.

Figure 7 shows the box-plot comparison of the above four scenarios with respect to the three KGE components, $g_{1}, g_{2}$, and $g_{3}$. For correlation component $g_{1}$, calibration scenario has the highest overall contribution value (median $g_{1}=0.85$ ), and is followed by temporal (median $g_{1}=0.68$ ), spatial (median $g_{1}=0.54$ ), and spatiotemporal (median $g_{1}=$ 

contribution value (median $g_{2}=0.06$ ), and is followed by the temporal (median $g_{2}=0.17$ ), spatial (median $g_{2}=0.23$ ), and spatiotemporal (median $g_{2}=0.24$ ) transfer schemes. The bias component $g_{3}$ has a similar trend as $g_{2}$, but is less prominent. The calibration scenario has the lowest contribution value (median $g_{3}=0.05$ ), and is followed by the temporal (median $g_{3}=0.11$ ), spatial (median $g_{3}=0.12$ ), and spatiotemporal (median $g_{3}=0.13$ ) transfer schemes.

Results from Figures 6 and 7 demonstrate that the overall model performance of the temporal parameter transfer scheme is superior to that of the spatial and spatiotemporal parameter transfer schemes. However, it is not clear from these results whether our experimental setup provides any undue advantage to the temporal parameter transfer scheme over the other two schemes. Below, we briefly mention two such potential scenarios:

Scenario 1: It is likely that for some of our study catchments, the distance between them and their nearest neighbour catchment is too high. Such a scenario puts the spatial and spatiotemporal transfer schemes at a clear disadvantage compared to the temporal transfer scheme.

Scenario 2: There is no temporal lag between calibration periods 1 and 2, i.e., calibration period 2 immediately follows calibration period 1 (Figure $2 b$ ). For catchments where the meteorological input patterns have not changed much across the two periods, the temporal parameter transfer scheme is much more likely to outperform the other two schemes. To mitigate the impacts from above two potential scenarios on our results, we repeat the parameter transfer experiment for the two following special conditions: more than $50 \mathrm{~km}$ away. The $50 \mathrm{~km}$ distance limit is slightly less than the median nearest 
neighbour distance $(53.1 \mathrm{~km})$ among all the 294 study catchments. This reduces the number of catchments from 294 to 138.

Special Condition 2: Shorten the calibration period 1 to span from WY 1971 to 1975 (instead of WY 1971 to 1978) and calibration period 2 to span from WY 1984 to 1988 (instead of WY 1979 to 1988). This creates a temporal lag of 8 years between the two calibration periods.

Nonetheless, unlike Special Condition 1, all 294 study catchments are used for simulations.

Note that these new calibration periods span 5 years each, which is the minimum time span recommended by some studies to adequately capture the temporal hydrological variability of a catchment [Merz et al., 2009].

Figures $8 \mathrm{a}$ and $8 \mathrm{~b}$ show the box-plot comparison of KGE values from the four modelling scenarios for Special Conditions 1 and 2 respectively. In both cases, the results are similar to those observed in Figure 6. For Special Condition 1, the highest model performance is obtained for the calibration scenario (median $\mathrm{KGE}=0.74$ ), followed by the temporal (median KGE $=0.71$; decline of $4 \%$ ), spatial $($ median $\mathrm{KGE}=0.67$; decline of 9.5\%), and spatiotemporal (median $\mathrm{KGE}=0.66$; decline of $10.8 \%$ ) parameter transfer schemes. For Special Condition 2, the median KGE values are 0.72 for calibration, 0.66 for temporal transfer scheme (decline of $8.3 \%$ ), 0.62 for spatial transfer scheme (decline of $13.9 \%$ ), and 0.62 for spatiotemporal transfer scheme (decline of $13.9 \%$ ).

\section{Discussion}

Comparison of the optimal KGE values (Figure 3) and the individual KGE components (Figure 4) between calibration periods 1 and 2 demonstrates that the performance of a hydrological model can, at least in some cases, vary considerably in the same catchment for different calibration periods. Similar findings have been reported by Vaze et al. [2010] and Razavi and Tolson [2013]. The data points shown in Figures 3 and 4 
are scattered along both sides of the 1:1 line. This suggests that for our study catchments no systematic bias exists in terms of one calibration period providing better calibration performance than the other. For the majority of study catchments (213 out of 294), the difference between optimal KGE values for the two calibration periods is less than $10 \%$ (median $=6 \%$ ). This is consistent with Merz et al. [2011], who found that the calibrated Nash-Sutcliffe efficiency values [Nash and Sutcliffe, 1970] of the HBV model, averaged across their 273 Austrian catchments, showed small variability across six different calibration periods. However, they found this variability to increase when only drier study catchments were considered in their calculations. Although our data set does have a few catchments that show large performance difference between the calibration periods (largest difference is $35 \%$ ), we did not detect any specific geographic or climatic pattern among those catchments. Results from Figure 5 show that the temporal variability of parameter values is different for each parameter, with values of the $f$ parameter showing the highest correlation (and therefore lowest variability) between the two calibration periods, followed by $S_{\max }, D_{f}$, $Q_{\max }, T_{\min }$, and $T_{\max }$. Interestingly, this trend is similar to the parameter sensitivity trend shown in our previous study [Patil and Stieglitz, 2014]. Patil and Stieglitz [2014] performed a sensitivity analysis of all 6 EXP-HYDRO parameters and found that $f, S_{\max }$, and $D_{f}$ were the most sensitive parameters (i.e., sensitive to the objective function) with better defined optimal values and posterior distributions. On the other hand, $Q_{\max }, T_{\min }$, and $T_{\max }$ were characterised as the insensitive parameters with virtually no difference between their prior (uniform) and posterior distributions. Combined, these results suggest that the high sensitivity model parameters are also more likely to have low variability across different calibration periods, thereby making them more representative of the catchment's intrinsic physiographic conditions rather than the specific input conditions during the calibration 
period. For the EXP-HYDRO model, the two most temporally stable parameters ( $f$ and

$332 S_{\max }$ ) represent: (1) the rate of storage decline within the soil bucket in response to subsurface runoff, and (2) the total soil bucket capacity. Both these parameters are, at least in theory, linked to the intrinsic soil and topographic properties of a catchment that are unlikely to undergo drastic temporal change. Nonetheless, we suspect that the proportion of sensitive and temporally stable parameters is likely to be different for different types of hydrological models. For instance, Merz and Blöschl [2004] calibrated the lumped version of HBV model (containing 11 parameters) at 308 catchments in Austria for two different calibration periods. They found that the correlation coefficient $\left(\mathrm{R}^{2}\right)$ between the parameter values of the two calibration periods ranged from 0.09 to 0.64 , with only 5 of the 11 parameters having $\mathrm{R}^{2}>$ 0.5. Oudin et al. [2008] compared the parameters of two spatially lumped hydrological models, GR4J (4 parameters) and TOPMO (6 parameters), for 913 French catchments across two calibration periods, and showed that the correlation across calibration periods was higher for GR4J parameters compared to TOPMO parameters. However, it must be noted we still do not have a complete understanding of how these model parameter values will change in response to land cover changes within a catchment [Eckhardt et al., 2003; Croke et al., 2004; Wang and Kalin, 2011].

Results from the parameter transfer experiment (Figures 6 and 7) demonstrate the overall superior performance of the temporal parameter transfer scheme over the spatial and spatiotemporal parameter transfer schemes. Analysis of the three KGE components (Figure 7) shows that the correlation component $\left(g_{1}\right)$ is the most dominant contributor to KGE value, which is consistent with Gupta et al. [2009]. However, this component also undergoes the most decline when moving away from calibration to the parameter transfer scenarios. The decline in $g_{1}$ is compensated by a proportional increase in the contribution from the other two 
components (variability $g_{2}$ and bias $g_{3}$ ) for the parameter transfer scenarios compared to calibration. Gupta et al. [2009] note that the relative contributions of the bias and variability components tend to increase for non-optimal parameter sets, as is observed in all our parameter transfer scenarios. When the three parameter transfer schemes are individually compared across each of the 294 catchments, the temporal transfer scheme shows best performance at 204 catchments (and worst at 50 catchments), the spatial transfer scheme is best at 65 catchments (and worst at 106 catchments), whereas the spatiotemporal transfer scheme is best at 27 catchments (and worst at 147 catchments). Figure 9 shows the map of catchment locations where either the spatial or spatiotemporal parameter transfer scheme is the best performing scheme. No specific geographic pattern is noticeable from this figure in terms of the catchments that prefer the spatial and spatiotemporal transfer schemes over the temporal transfer scheme. Table 1 shows the comparison of these two catchment groups (Group 1: spatial or spatiotemporal transfer scheme performing best; Group 2: temporal transfer scheme performing best) with respect to three commonly used hydro-climatic metrics, viz., mean annual rainfall $(\mathrm{P})$, annual runoff ratio $(\mathrm{Q} / \mathrm{P})$ and climate aridity index (PET/P). Although the median values of these metrics suggest that Group 1 catchments are slightly drier (lower P and higher PET/P) and flashier (higher $\mathrm{Q} / \mathrm{P}$ ), there does not seem to be much difference among the two catchment groups. Nonetheless, Figure 9 clearly illustrates that even in regions with low catchment density and larger distances among neighbouring catchments (e.g., in the western US), the temporal parameter transfer schemes does not always outperform the spatial and spatiotemporal schemes.

Parameter transfer experiments under the two special conditions (see Section 3) show that the temporal parameter transfer scheme still preserves its advantage over the spatial and spatiotemporal schemes. For Special Condition 1, i.e., when only those catchments with nearest neighbour $<50 \mathrm{~km}$ away are retained, the spatial and spatiotemporal schemes exhibit 
performance improvement as the KGE difference between them and calibration is about $3 \%$ lower than the base scenario. This is an expected result because lower spatial distances between catchments will most likely reduce the spatial variability of hydrological behaviour [Oudin et al., 2008]. On the other hand, for Special Condition 2 (when the temporal gap between calibration periods is increased to 8 years), the KGE difference between calibration and the temporal scheme is about $4 \%$ higher than the base scenario, and is virtually unchanged between calibration and the spatial and spatiotemporal schemes. Thus, an increase in the temporal distance between calibration and validation periods reduces the model performance gap between the temporal scheme and the spatial and spatiotemporal calibration and validation periods (as is common in climate change scenarios) has the potential to make spatiotemporal parameter transfer a more viable option than temporal parameter transfer. However, even though the introduction of an 8 year temporal gap larger (> 40-50 years) temporal gaps. hydrological model called EXP-HYDRO at 294 catchments across the continental United States. In our view, such a comparison is highly relevant especially within the context of increasing appeal and popularity of the "trading space for time" framework proposed for assessing the hydrological implications of anthropogenic climate change. Results showed 
that the temporal parameter transfer scheme performs best, with lowest decline in prediction performance compared to calibration (median decline of $4.2 \%$ ); whereas negligible difference in prediction performance was observed between the spatial and spatiotemporal parameter transfer schemes (median decline of $12.4 \%$ and $13.9 \%$ respectively). These results suggest that the stability of hydrological model parameters tends to be higher in the temporal domain than in the spatial domain, and are consistent with previous studies conducted in different parts of the world [Parajka et al., 2005; Zhang and Chiew, 2009]. We also demonstrated that the relative superiority of temporal parameter transfer scheme is preserved even when: (1) the spatial distance between donor and receiver catchments is reduced, or (2) the temporal lag between calibration and validation periods is increased. Nonetheless, we found that an increase in the temporal lag between calibration and validation periods reduces the model performance gap between the temporal scheme and the spatial and spatiotemporal schemes. This finding, combined with the negligible difference observed between the spatial and spatiotemporal schemes, suggest that spatiotemporal transfer of hydrological model parameters has the potential to be a viable option for climate change related studies, as envisioned in the trading space for time framework. However, further research is still needed to better understand the relationship between the spatial and temporal aspects of catchment hydrological variability with increasing time lag between the calibration and validation periods.

\section{Acknowledgements}

We are thankful to Mark Rayment and an anonymous reviewer for providing valuable comments and suggestions that have greatly improved this paper. This research was supported in part by the US National Science Foundation (NSF) grants 0922100 and 
1027870. Mention of trade names or commercial products does not constitute endorsement

430

431

432

433

434

435

436

437

438

439

440

441

442

443

444

445

446

447

448

449

450

451

452

453

454

455

456

457

458

459

460

461

or recommendation for use.

\section{References}

Beven, K. J. (2001), Rainfall-runoff modelling: the primer, Wiley, Chichester.

Blöschl, G., M. Sivapalan, and T. Wagener (2013), Runoff prediction in ungauged basins: synthesis across processes, places and scales, Cambridge University Press.

Brigode, P., L. Oudin, and C. Perrin (2013), Hydrological model parameter instability: A source of additional uncertainty in estimating the hydrological impacts of climate change?, J. Hydrol., 476, 410-425, doi:10.1016/j.jhydrol.2012.11.012.

Coron, L., V. Andréassian, C. Perrin, J. Lerat, J. Vaze, M. Bourqui, and F. Hendrickx (2012), Crash testing hydrological models in contrasted climate conditions: An experiment on 216 Australian catchments, Water Resour. Res., 48(5), W05552, doi:10.1029/2011WR011721.

Croke, B. F. W., W. S. Merritt, and A. J. Jakeman (2004), A dynamic model for predicting hydrologic response to land cover changes in gauged and ungauged catchments, $J$. Hydrol., 291(1-2), 115-131, doi:http://dx.doi.org/10.1016/j.jhydrol.2003.12.012.

Eckhardt, K., L. Breuer, and H. G. Frede (2003), Parameter uncertainty and the significance of simulated land use change effects, J. Hydrol., 273(1-4), 164-176, doi:10.1016/S00221694(02)00395-5.

Ehret, U. et al. (2014), Advancing catchment hydrology to deal with predictions under change, Hydrol. Earth Syst. Sci., 18(2), 649-671, doi:10.5194/hess-18-649-2014.

Gill, M. K., Y. H. Kaheil, A. Khalil, M. McKee, and L. Bastidas (2006), Multiobjective particle swarm optimization for parameter estimation in hydrology, Water Resour. Res., 42(7), W07417, doi:10.1029/2005WR004528.

Goswami, M., and K. M. O’Connor (2007), Comparative assessment of six automatic optimization techniques for calibration of a conceptual rainfall—runoff model, Hydrol. Sci. J., 52(3), 432-449, doi:10.1623/hysj.52.3.432.

Gupta, H. V., H. Kling, K. K. Yilmaz, and G. F. Martinez (2009), Decomposition of the mean squared error and NSE performance criteria: Implications for improving hydrological modelling, J. Hydrol., 377(1-2), 80-91, doi:10.1016/j.jhydrol.2009.08.003.

Hamon, W. R. (1963), Computation of direct runoff amounts from storm rainfall, Int. Assoc. Sci. Hydrol. Publ, 63, 52-62. 
Hrachowitz, M. et al. (2013), A decade of Predictions in Ungauged Basins (PUB) - a review, Hydrol. Sci. J., 58(6), 1198-1255, doi:10.1080/02626667.2013.803183.

Juston, J., J. Seibert, and P.-O. Johansson (2009), Temporal sampling strategies and uncertainty in calibrating a conceptual hydrological model for a small boreal catchment, Hydrol. Process., 23(21), 3093-3109, doi:10.1002/hyp.7421.

Kennedy, J., and R. Eberhart (1995), Particle swarm optimization, in IEEE International Conference on Neural Networks Proceedings, Vols 1-6, pp. 1942-1948.

Klemeš, V. (1986), Operational testing of hydrological simulation models, Hydrol. Sci. J., 31(1), 13-24, doi:10.1080/02626668609491024.

Kokkonen, T. S., A. J. Jakeman, P. C. Young, and H. J. Koivusalo (2003), Predicting daily flows in ungauged catchments: model regionalization from catchment descriptors at the Coweeta Hydrologic Laboratory, North Carolina, Hydrol. Process., 17, 2219-2238, doi:10.1002/hyp.1329.

Liu, Y. (2009), Automatic calibration of a rainfall-runoff model using a fast and elitist multiobjective particle swarm algorithm, Expert Syst. Appl., 36(5), 9533-9538, doi:10.1016/j.eswa.2008.10.086.

Maurer, E. P., A. W. Wood, J. C. Adam, D. P. Lettenmaier, and B. Nijssen (2002), A LongTerm Hydrologically Based Dataset of Land Surface Fluxes and States for the Conterminous United States, J. Clim., 15, 3237-3251, doi:10.1175/15200442(2002)015<3237:althbd >2.0.co;2.

McIntyre, N., H. Lee, H. Wheater, A. Young, and T. Wagener (2005), Ensemble predictions of runoff in ungauged catchments, Water Resour. Res., 41, W12434, doi:10.1029/2005wr004289.

Merz, R., and G. Blöschl (2004), Regionalisation of catchment model parameters, J. Hydrol., 287(1-4), 95-123, doi:10.1016/j.jhydrol.2003.09.028.

Merz, R., J. Parajka, and G. Blöschl (2009), Scale effects in conceptual hydrological modeling, Water Resour. Res., 45(9), W09405, doi:10.1029/2009WR007872.

Merz, R., J. Parajka, and G. Blöschl (2011), Time stability of catchment model parameters: Implications for climate impact analyses, Water Resour. Res., 47(2), W02531, doi:10.1029/2010WR009505.

Montanari, A. et al. (2013), "Panta Rhei-Everything Flows": Change in hydrology and society-The IAHS Scientific Decade 2013-2022, Hydrol. Sci. J., 58(6), 1256-1275, doi:10.1080/02626667.2013.809088.

Nash, J. E., and J. V Sutcliffe (1970), River flow forecasting through conceptual models part I - A discussion of principles, J. Hydrol., 10, 282-290, doi:10.1016/00221694(70)90255-6. 
Oudin, L., V. Andreassian, C. Perrin, C. Michel, and N. Le Moine (2008), Spatial proximity, physical similarity, regression and ungaged catchments: A comparison of regionalization approaches based on 913 French catchments, Water Resour. Res., 44(3), W03413W03413, doi:10.1029/2007WR006240.

Parajka, J., R. Merz, and G. Blöschl (2005), A comparison of regionalisation methods for catchment model parameters, Hydrol. Earth Syst. Sci., 9(3), 157-171.

Patil, S., and M. Stieglitz (2012), Controls on hydrologic similarity: role of nearby gauged catchments for prediction at an ungauged catchment, Hydrol. Earth Syst. Sci., 16(2), 551-562, doi:10.5194/hess-16-551-2012.

Patil, S., and M. Stieglitz (2014), Modelling daily streamflow at ungauged catchments: what information is necessary?, Hydrol. Process., 28(3), 1159-1169, doi:10.1002/hyp.9660.

Patil, S. D., P. J. Wigington, S. G. Leibowitz, E. A. Sproles, and R. L. Comeleo (2014a), How does spatial variability of climate affect catchment streamflow predictions?, $J$. Hydrol., 517, 135-145, doi:10.1016/j.jhydrol.2014.05.017.

Patil, S. D., P. J. Wigington, S. G. Leibowitz, and R. L. Comeleo (2014b), Use of Hydrologic Landscape Classification to Diagnose Streamflow Predictability in Oregon, JAWRA J. Am. Water Resour. Assoc., 50(3), 762-776, doi:10.1111/jawr.12143.

Peel, M. C., and G. Blöschl (2011), Hydrological modelling in a changing world, Prog. Phys. Geogr. , 35 (2), 249-261.

Post, D. A., and A. J. Jakeman (1999), Predicting the daily streamflow of ungauged catchments in S.E. Australia by regionalising the parameters of a lumped conceptual rainfall-runoff model, Ecol. Modell., 123(2-3), 91-104, doi:10.1016/S03043800(99)00125-8.

Razavi, S., and B. A. Tolson (2013), An efficient framework for hydrologic model calibration on long data periods, Water Resour. Res., 49(12), 8418-8431, doi:10.1002/2012WR013442.

Refsgaard, J. C. (1997), Parameterisation, calibration and validation of distributed hydrological models, J. Hydrol., 198(1-4), 69-97, doi:10.1016/S0022-1694(96)03329$\mathrm{X}$.

Refsgaard, J. C., and J. Knudsen (1996), Operational Validation and Intercomparison of Different Types of Hydrological Models, Water Resour. Res., 32, 2189-2202, doi:10.1029/96wr00896.

Refsgaard, J. C. et al. (2014), A framework for testing the ability of models to project climate change and its impacts, Clim. Change, 122(1-2), 271-282, doi:10.1007/s10584-0130990-2.

Singh, R., T. Wagener, K. van Werkhoven, M. E. Mann, and R. Crane (2011), A tradingspace-for-time approach to probabilistic continuous streamflow predictions in a 
changing climate - accounting for changing watershed behavior, Hydrol. Earth Syst. Sci., 15(11), 3591-3603, doi:10.5194/hess-15-3591-2011.

Singh, R., K. van Werkhoven, and T. Wagener (2014), Hydrological impacts of climate change in gauged and ungauged watersheds of the Olifants basin: a trading-space-fortime approach, Hydrol. Sci. J., 59(1), 29-55, doi:10.1080/02626667.2013.819431.

Sivapalan, M. et al. (2003), IAHS Decade on Predictions in Ungauged Basins (PUB), 20032012: Shaping an exciting future for the hydrological sciences, Hydrol. Sci. J., 48, 857880, doi:10.1623/hysj.48.6.857.51421.

Slack, J. R., A. Lumb, and J. M. Landwehr (1993), Hydro-Climatic Data Network (HCDN) Streamflow Data Set, 1874-1988:, U.S. Geological Survey, Reston, VA.

Vaze, J., D. A. Post, F. H. S. Chiew, J.-M. Perraud, N. R. Viney, and J. Teng (2010), Climate non-stationarity - Validity of calibrated rainfall-runoff models for use in climate change studies, J. Hydrol., 394(3-4), 447-457, doi:10.1016/j.jhydrol.2010.09.018.

Wagener, T., and H. S. Wheater (2006), Parameter estimation and regionalization for continuous rainfall-runoff models including uncertainty, J. Hydrol., 320, 132-154, doi:10.1016/j.jhydrol.2005.07.015.

Wagener, T., N. McIntyre, M. J. Lees, H. S. Wheater, and H. V Gupta (2003), Towards reduced uncertainty in conceptual rainfall-runoff modelling: dynamic identifiability analysis, Hydrol. Process., 17(2), 455-476, doi:10.1002/hyp.1135.

Wagener, T., M. Sivapalan, P. A. Troch, B. L. McGlynn, C. J. Harman, H. V Gupta, P. Kumar, P. S. C. Rao, N. B. Basu, and J. S. Wilson (2010), The future of hydrology: An evolving science for a changing world, Water Resour. Res., 46(5), W05301, doi:10.1029/2009WR008906.

Wang, R., and L. Kalin (2011), Modelling effects of land use/cover changes under limited data, Ecohydrology, 4(2), 265-276, doi:10.1002/eco.174.

Westra, S., M. Thyer, M. Leonard, D. Kavetski, and M. Lambert (2014), A strategy for diagnosing and interpreting hydrological model nonstationarity, Water Resour. Res., 50(6), 5090-5113, doi:10.1002/2013WR014719.

Xia, Y., Z.-L. Yang, C. Jackson, P. L. Stoffa, and M. K. Sen (2004), Impacts of data length on optimal parameter and uncertainty estimation of a land surface model, J. Geophys. Res. Atmos., 109(D7), D07101, doi:10.1029/2003JD004419.

Young, A. R. (2006), Stream flow simulation within UK ungauged catchments using a daily rainfall-runoff model, J. Hydrol., 320, 155-172, doi:10.1016/j.jhydrol.2005.07.017.

Zhang, X., R. Srinivasan, K. Zhao, and M. Van Liew (2009), Evaluation of global optimization algorithms for parameter calibration of a computationally intensive hydrologic model, Hydrol. Process., 23(3), 430-441, doi:10.1002/hyp.7152. 
571 Zhang, Y., and F. H. S. Chiew (2009), Relative merits of different methods for runoff predictions in ungauged catchments, Water Resour. Res., 45, W07412-W07412, 573 doi:10.1029/2008WR007504.

574

575 
576 Table 1: Comparison of the two catchment groups (from Figure 9) in terms of mean annual 577 rainfall, annual runoff ratio and climate aridity index.

\begin{tabular}{|l|c|c|c|}
\hline Catchment group & $\begin{array}{c}\text { Median value of } \\
\text { mean annual } \\
\text { rainfall (P) }\end{array}$ & $\begin{array}{c}\text { Median value of } \\
\text { annual runoff ratio } \\
\text { (Q/P) }\end{array}$ & $\begin{array}{c}\text { Median value of } \\
\text { climate aridity } \\
\text { index (PET/P) }\end{array}$ \\
\hline $\begin{array}{l}\text { Group 1: Spatial or } \\
\text { spatiotemporal transfer } \\
\text { performs best }\end{array}$ & $1110 \mathrm{~mm}$ & 0.43 & 0.73 \\
\hline $\begin{array}{l}\text { Group 2: Temporal } \\
\text { transfer performs best }\end{array}$ & $1185 \mathrm{~mm}$ & 0.41 & 0.69 \\
\hline
\end{tabular}




\section{Figures}

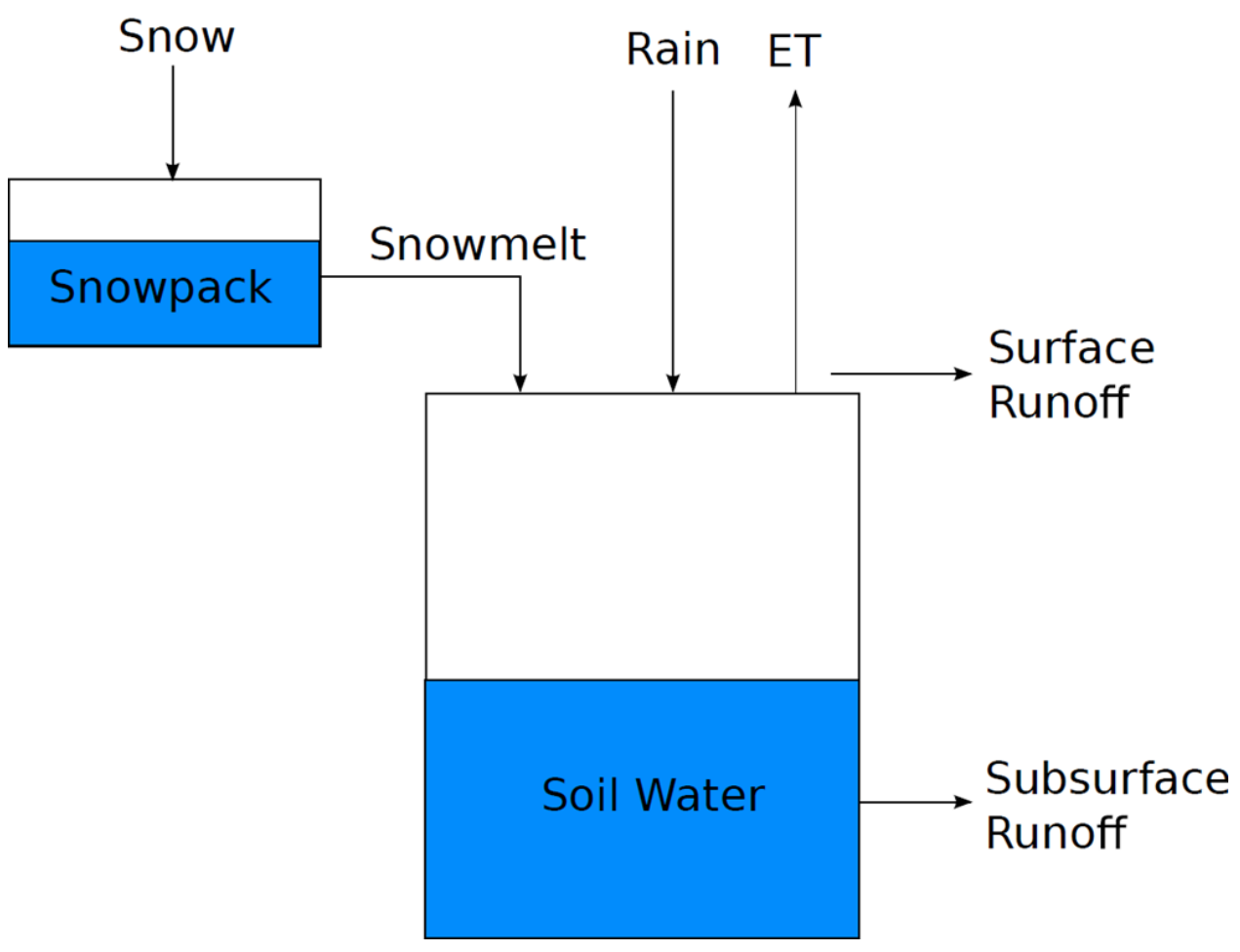

Figure 1: Overview of the EXP-HYDRO model components and fluxes (from Patil et al. [2014a]). 
a)

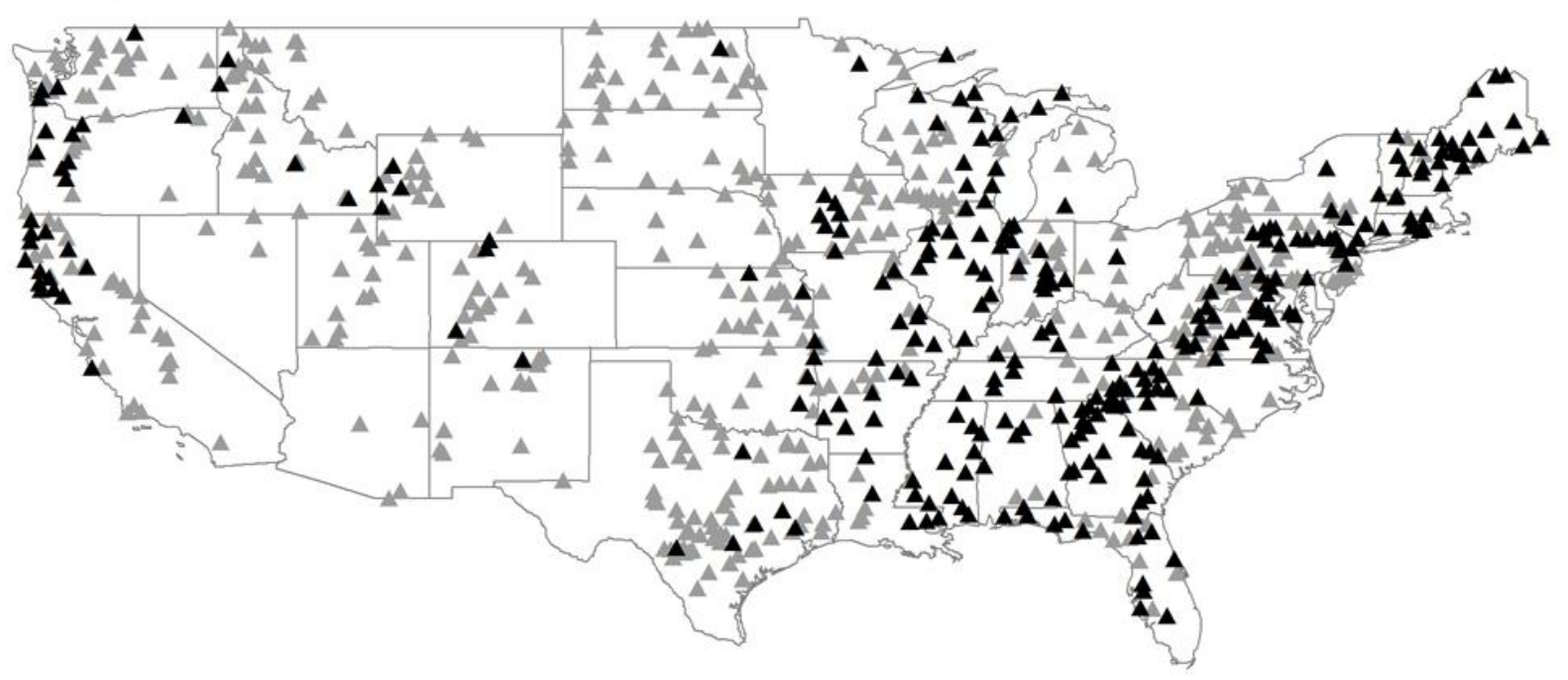

b)

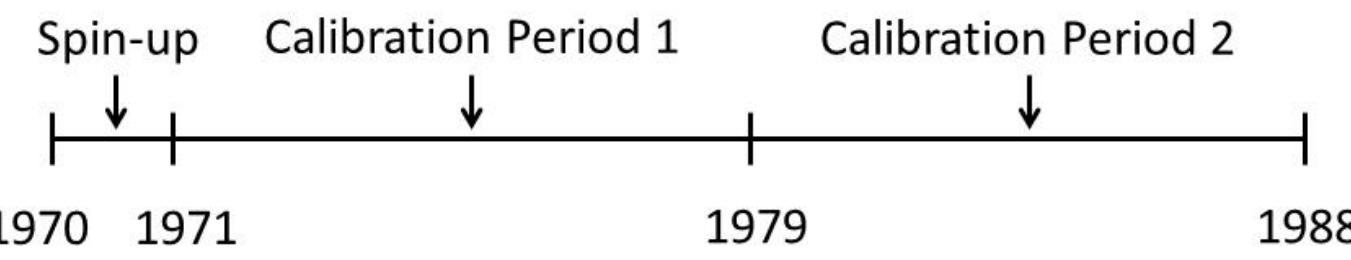

Figure 2: a) Location of all 756 catchments within the continental US where the EXPHYDRO model is implemented; the 294 study catchments that are retained for parameter transfer experiments are shown in black triangles, and b) Schematic representation of the timeline of the calibration periods. 


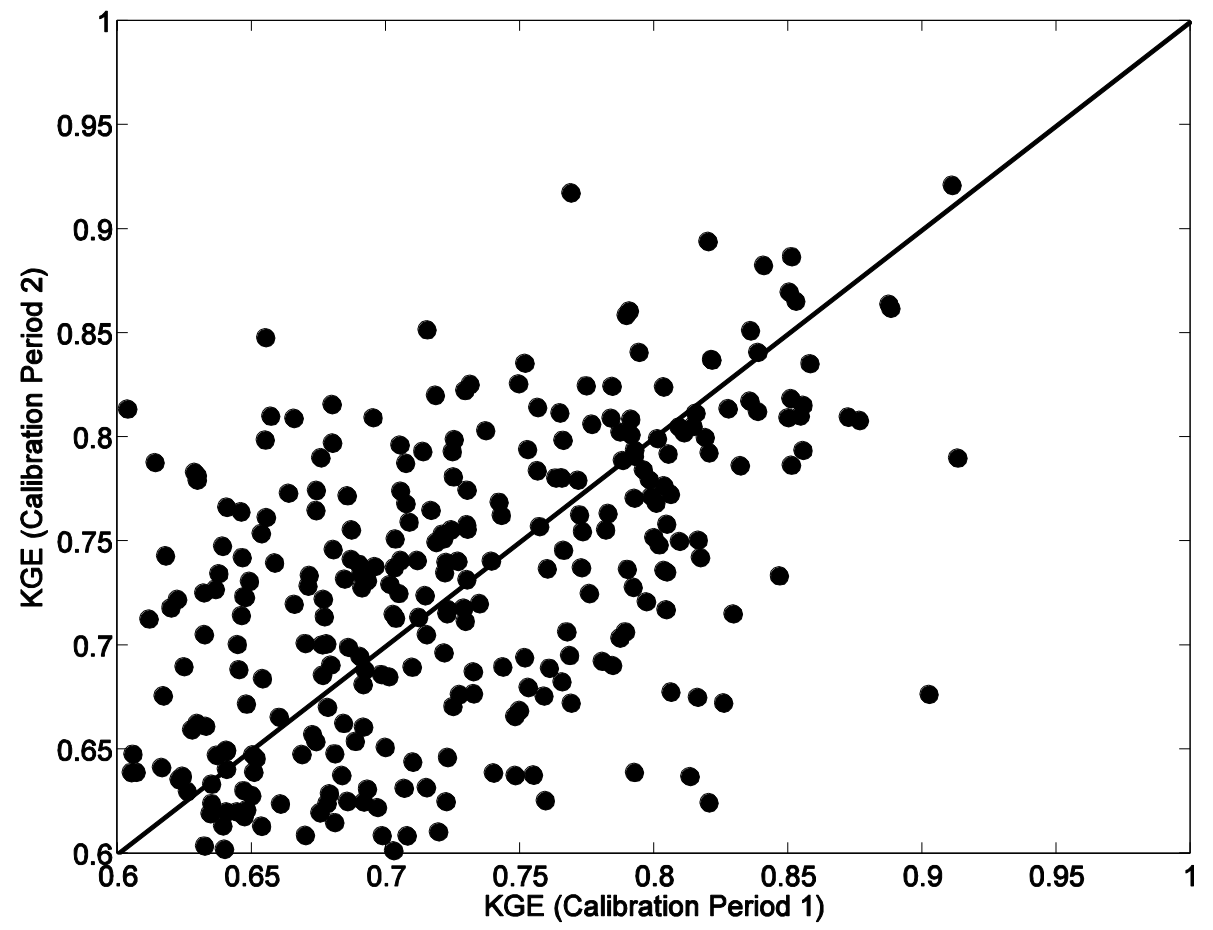

Figure 3: A 1:1 comparison of the KGE values for Calibration Periods 1 and 2. 
a) Correlation $\mathrm{g}_{1}$

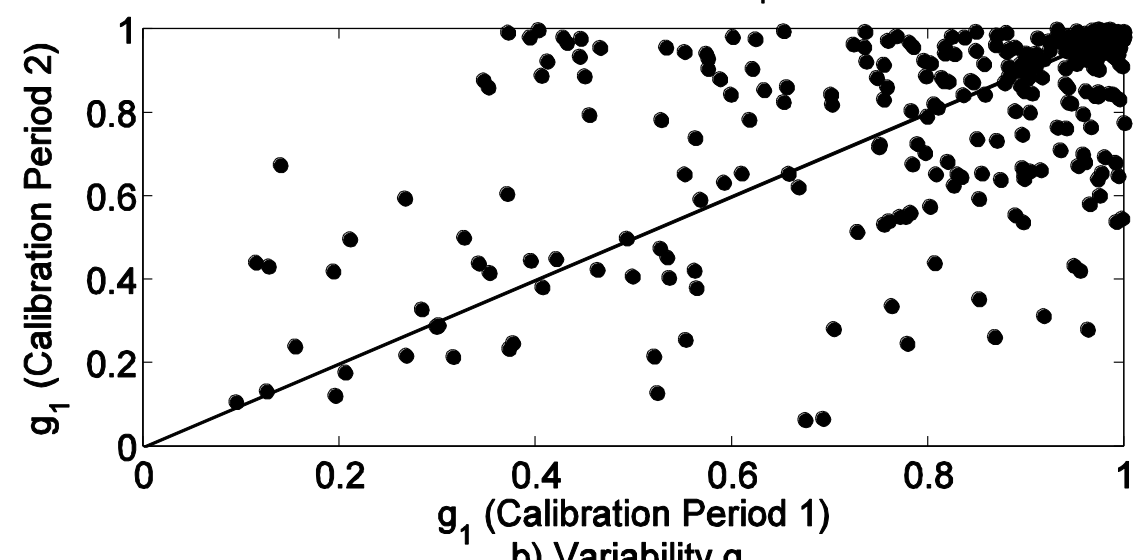

b) Variability $g_{2}$

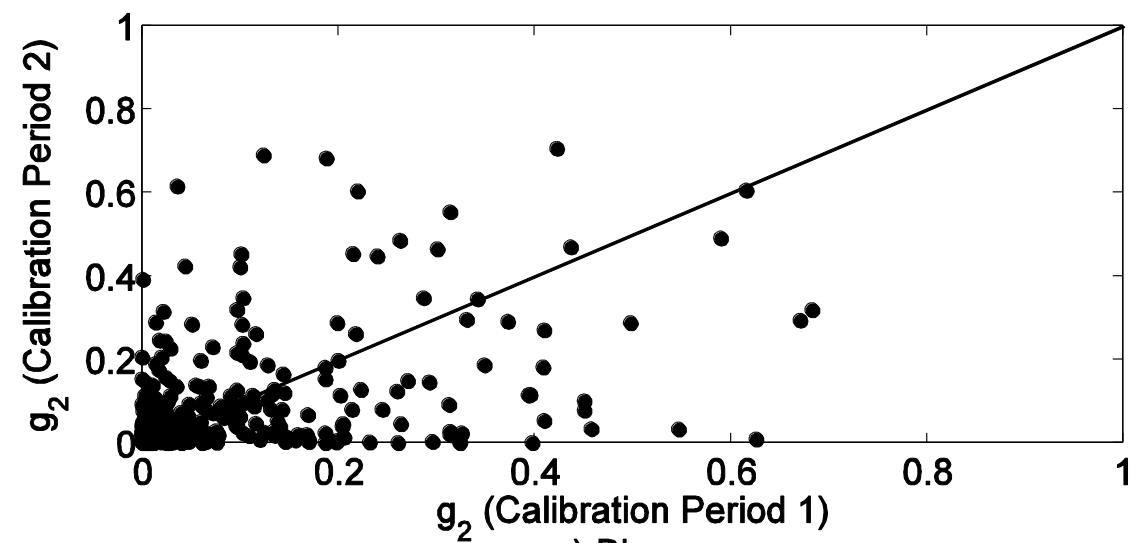

c) Bias $g_{3}$

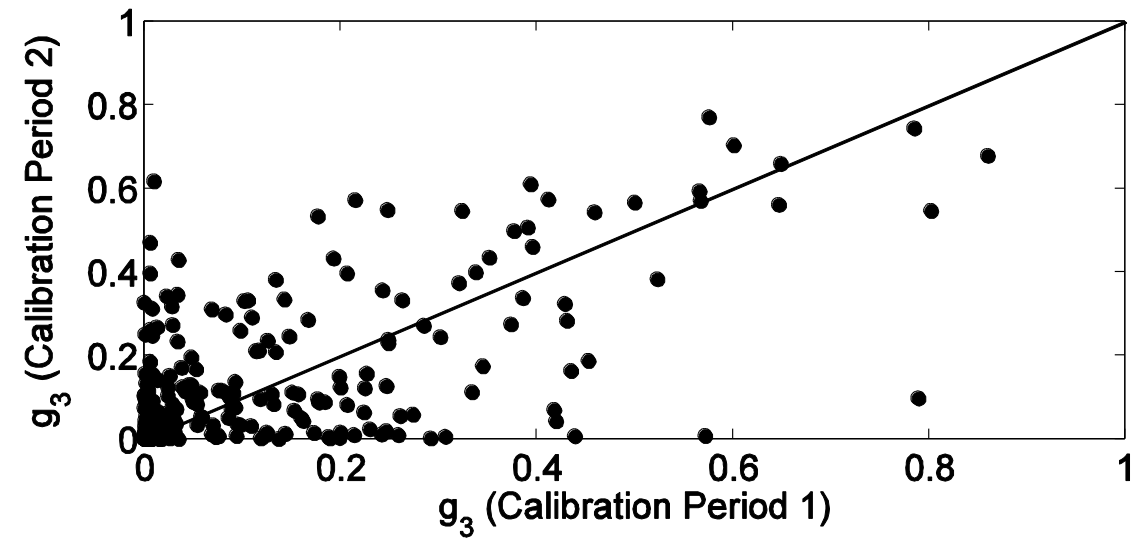

Figure 4: A 1:1 comparison of the three KGE components for Calibration Periods 1 and 2: a) Correlation $g_{1}$, b) Variability $g_{2}$, and c) Bias $g_{3}$. 

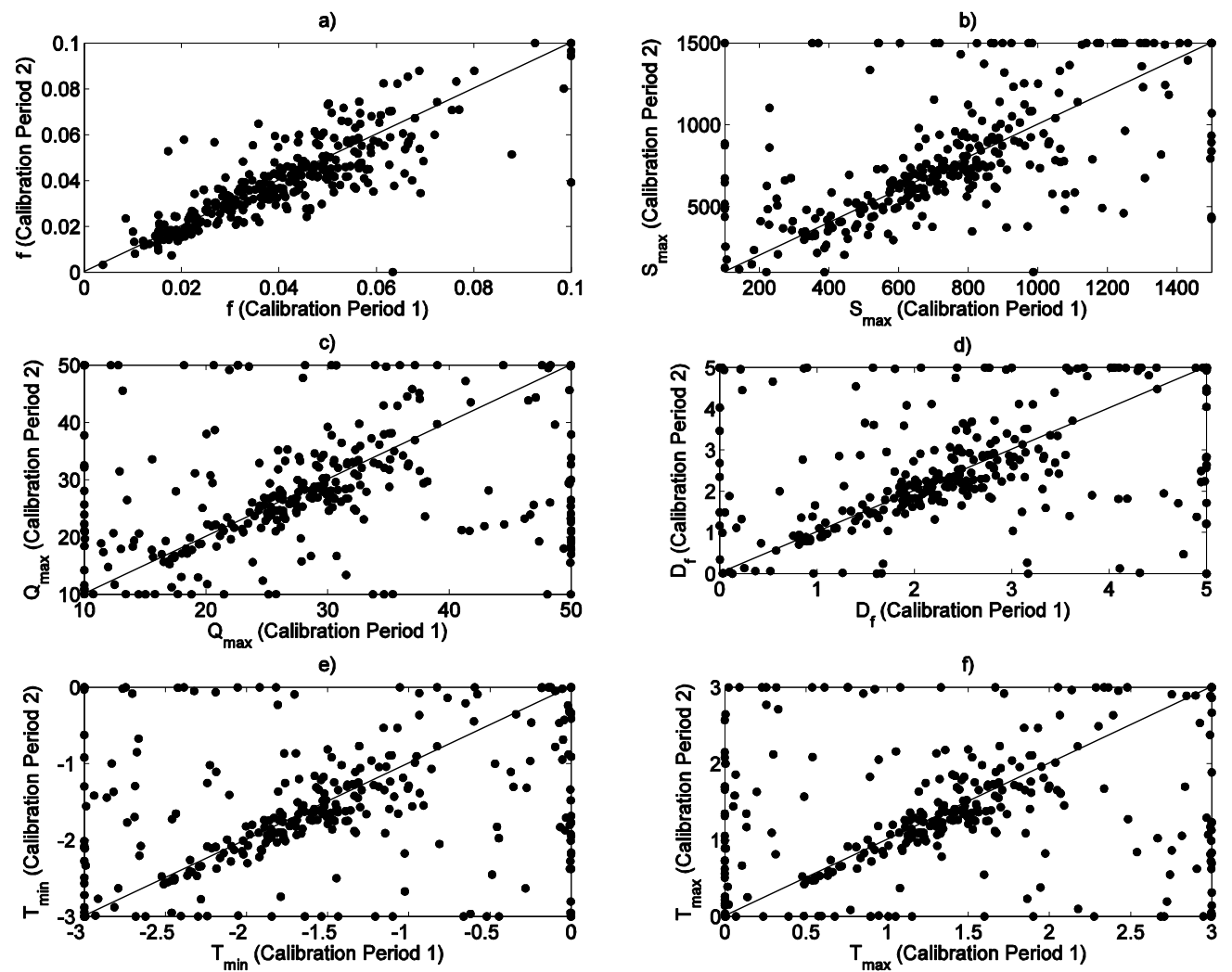

Figure 5: A 1:1 comparison of all 6 EXP-HYDRO parameter values for Calibration Periods 1 and 2. 


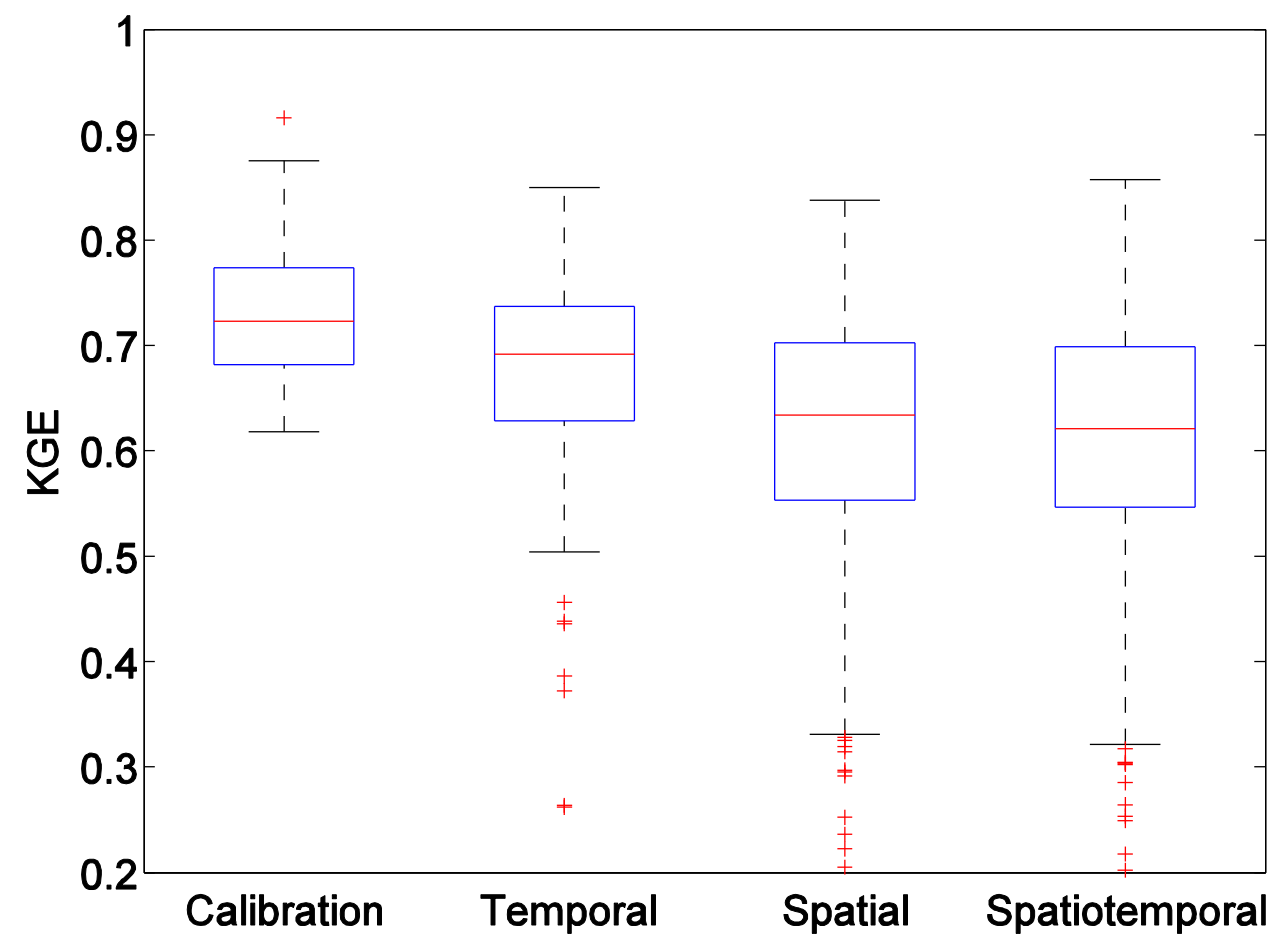

Figure 6: A box-plot comparison of the KGE values for calibration and the three parameter transfer scenarios. 
a)

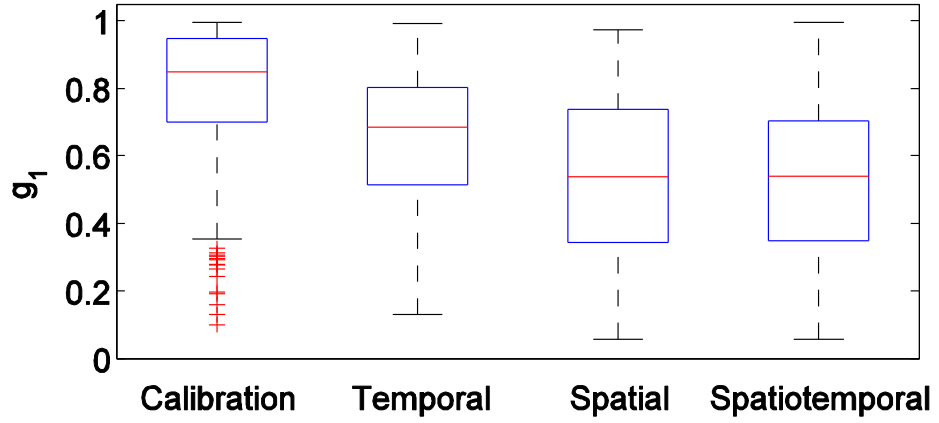

b)

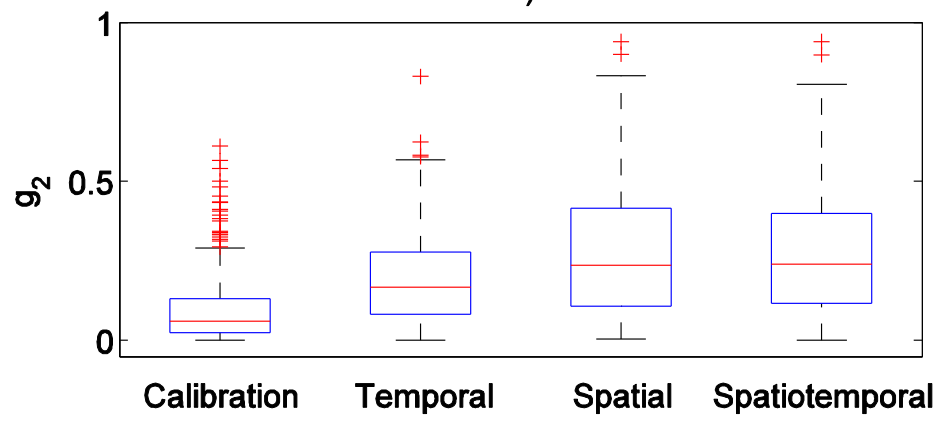

c)

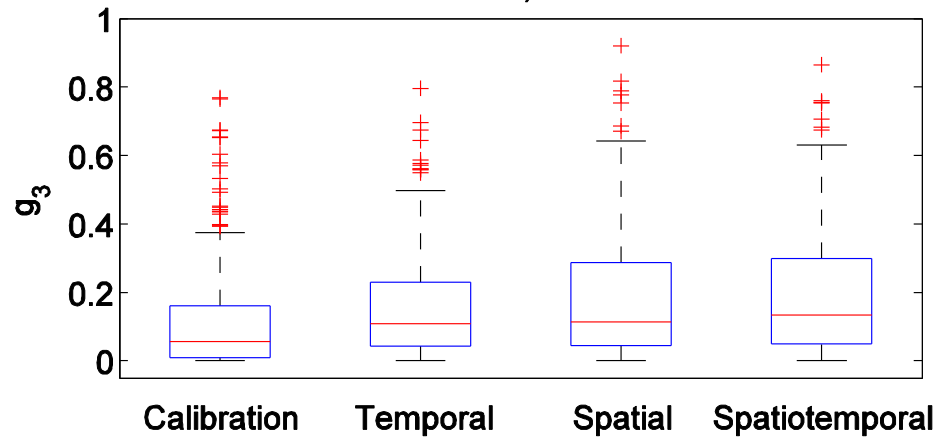

Figure 7: A box-plot comparison of the three KGE components for calibration and the three parameter transfer scenarios. 
a)

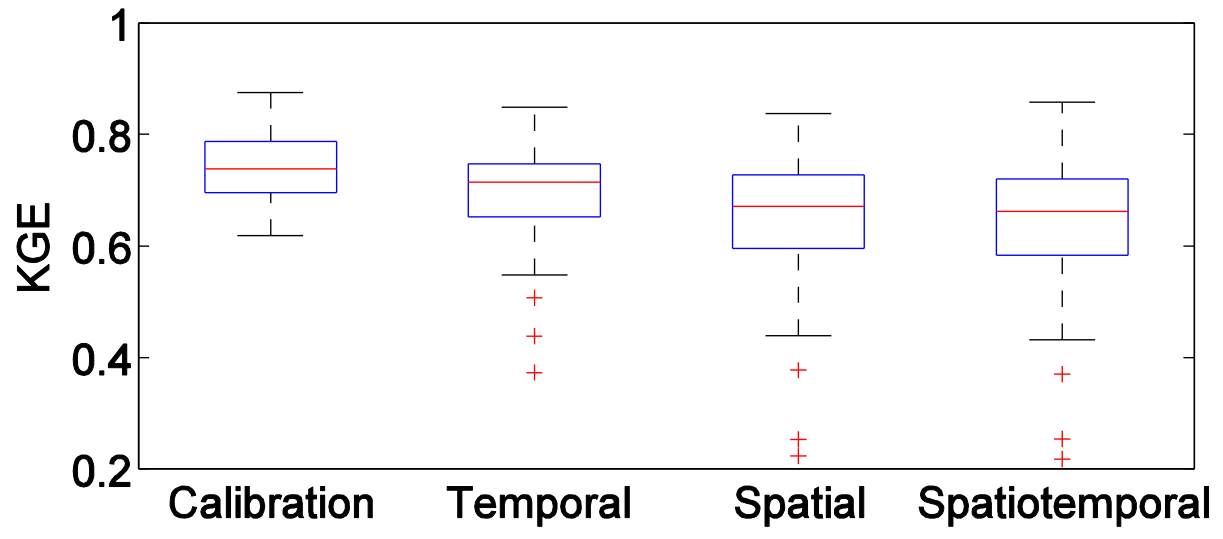

b)

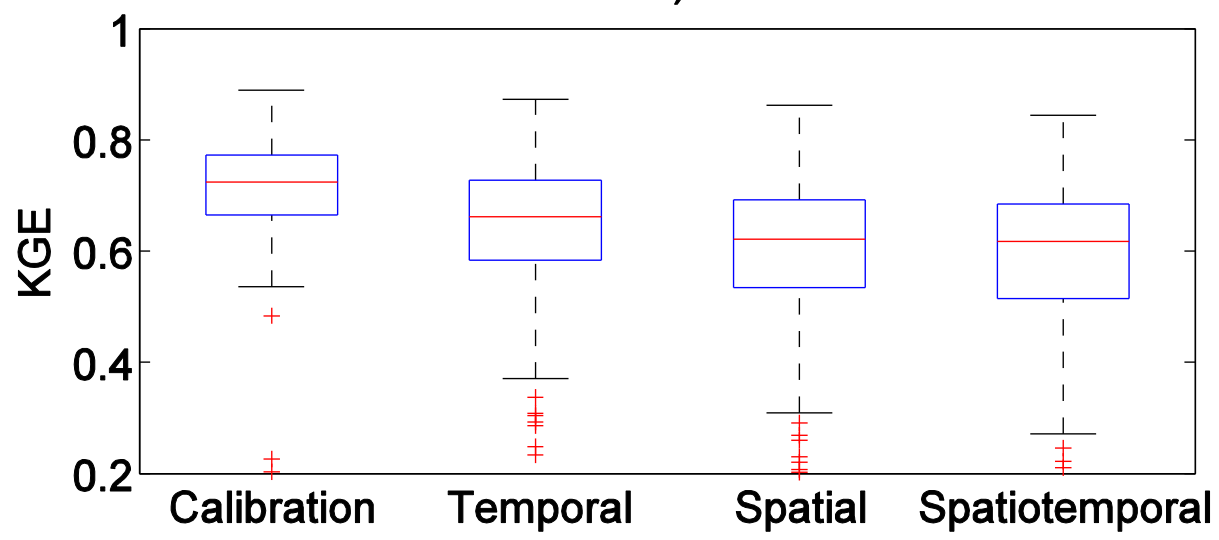

Figure 8: A box-plot comparison of the KGE values for calibration and the three parameter transfer scenarios, shown separately for a) Special Condition 1, and b) Special Condition 2. 


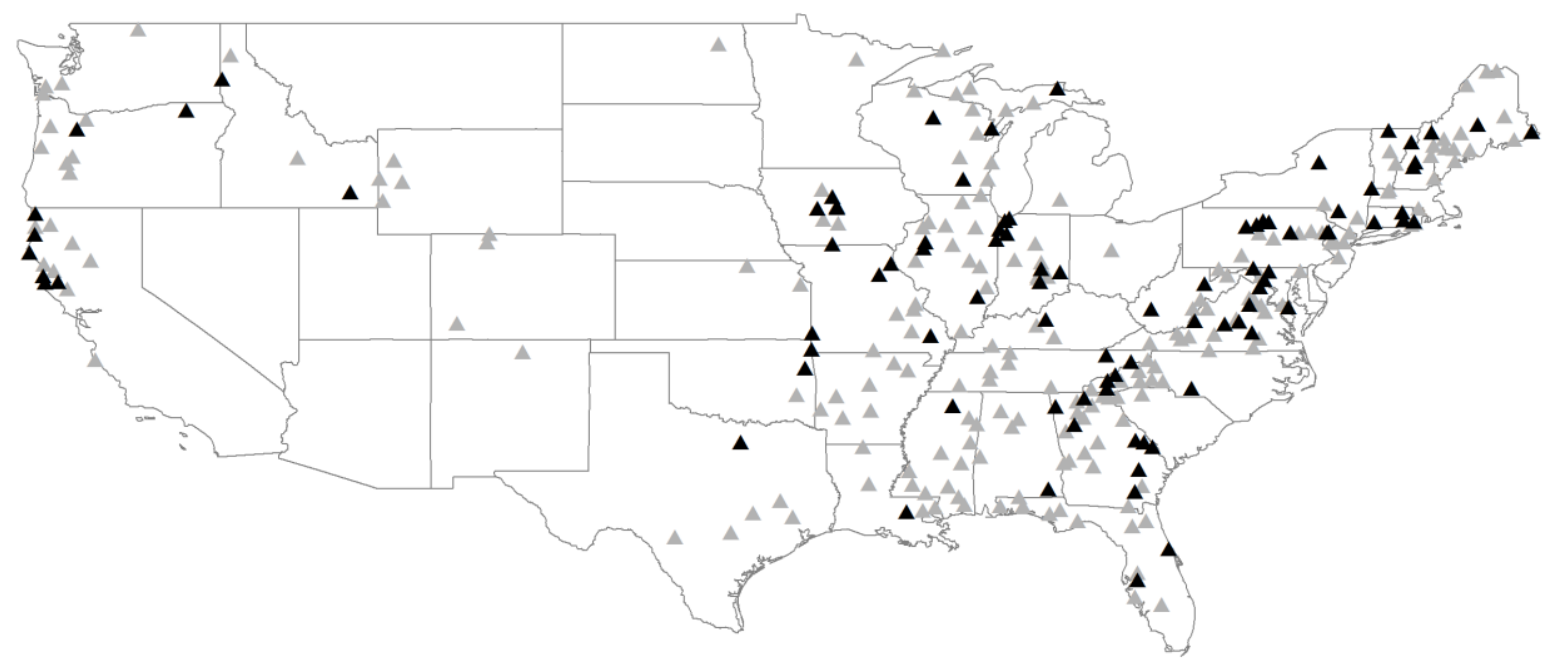

Figure 9: Location of the catchments where either the spatial or spatiotemporal parameter transfer scheme performs best (Black triangles). Catchments where the temporal parameter transfer scheme performs best are shown as grey triangles. 